\title{
Gestation, equality and freedom: ectogenesis as a political perspective
}

\author{
Giulia Cavaliere (1)
}

Medical School, Lancaster University, Lancaster, UK

\section{Correspondence to} Dr Giulia Cavaliere, Medical School, Lancaster University, Lancaster LA1 4YG, UK; g.cavaliere@lancaster.ac.uk

Received 8 July 2019 Revised 24 October 2019 Accepted 30 October 2019 Published Online First 8 November 2019

\section{SLinked}

- http://dx.doi.org/10.1136/ medethics-2019-105958

- http://dx.doi.org/10.1136/ medethics-2019-105959

- http://dx.doi.org/10.1136/ medethics-2019-105968

- http://dx.doi.org/10.1136/ medethics-2019-105981

- http://dx.doi.org/10.1136/ medethics-2020-106099

\section{Check for updates}

(C) Author(s) (or their employer(s)) 2020. No commercial re-use. See rights and permissions. Published by BMJ.

To cite: Cavaliere $\mathrm{G}$ $J$ Med Ethics 2020;46:76-82.

\section{ABSTRACT}

The benefits of full ectogenesis, that is, the gestation of human fetuses outside the maternal womb, for women ground many contemporary authors' arguments on the ethical desirability of this practice. In this paper, I present and assess two sets of arguments advanced in favour of ectogenesis: arguments stressing ectogenesis' equality-promoting potential and arguments stressing its freedom-promoting potential. I argue that although successfully grounding a positive case for ectogenesis, these arguments have limitations in terms of their reach and scope. Concerning their limited reach, I contend that ectogenesis will likely benefit a small subset of women and, arguably, not the group who most need to achieve equality and freedom. Concerning their limited scope, I contend that these defences do not pay sufficient attention to the context in which ectogenesis would be developed and that, as a result, they risk leaving the status quo unchanged. After providing examples of these limitations, I move to my proposal concerning the role of ectogenesis in promoting women's equality and freedom. This proposal builds on Silvia Federici's, Mariarosa Dalla Costa's and Selma James' readings of the international feminist campaign 'Wages for Housework'. It maintains that the political perspective and provocation that ectogenesis can advance should be considered and defended.

\section{INTRODUCTION: A(N ARGUABLY) DESIRABLE STATE OF AFFAIRS}

Imagine for a moment that it is possible to beget children without placing any kind of burden on women. Imagine a world where the health-related risks associated with pregnancy and childbirth have become obsolete. A world where the dietary and lifestyle changing behaviours necessary to maximise the chances of having healthy pregnancies would no longer be necessary. A world without the financial losses associated with maternity leave, and where the obstacles to career advancement that women currently face to gestate and give birth to children have disappeared. This arguably desirable state of affairs is what full ectogenesis ${ }^{\mathrm{i}}$ (henceforth 'ectogenesis ${ }^{\text {'ii }}$ ), namely, the gestation of human fetuses outside the maternal womb from conception to 'birth', may be able to deliver.

Ectogenesis is currently not technically possible. However, following Peter Singer and Deane Wells,

in this paper, I refer to 'full ectogenesis' as the gestation of human fetuses outside the maternal womb from conception to 'birth'. 'Partial ectogenesis' instead refers to the extrauterine gestation of a fetus after being removed from the maternal womb. ${ }^{i i}$ For an interesting terminological and conceptual analysis, see Elizabeth C. Romanis ${ }^{50}$ one could argue that "the period in which it is necessary for the human fetus to be in its mother's womb is shrinking from both sides". ${ }^{1}$ Experiments in embryology are pushing forward the time in which embryos can be sustained in vitro (on one side), while developments in non-human animals are pushing back the viability threshold (on the other side). The former set of experiments has demonstrated that embryos can be sustained in vitro for 12-13 days. ${ }^{23}$ This is longer than was hitherto technically possible and closer to the 14-day statutory limit to sustain embryos in vitro. ${ }^{4}$ On the other side, experiments in non-human animals have demonstrated that organisms such as lambs can be removed from the maternal womb and transferred in 'biobags' mimicking the condition of late-stage gestation. ${ }^{5}$ In these experiments, lambs have been removed at the corresponding viability threshold in humans (110 days for lambs, corresponding to 22-24 weeks for humans). The aims of this research are to better understand the conditions that enable extremely premature infants to survive outside the maternal womb and to improve their chances of survival. Taken together, developments in human embryology and in the extrauterine gestation of non-human animals are narrowing the time that organisms need to gestate in the maternal womb. Pace Singer and Wells, however, (full) ectogenesis currently remains a theoretical possibility. While such timeframe is indeed narrowing, technical, legal and ethical challenges remain to be addressed to shrink it further. One could then argue that the focus of the ethical debate should rather be on partial ectogenesis.

Despite this, this paper deliberately focuses on full rather than partial ectogenesis and on the normative arguments advanced in defence of this practice $^{\text {iii. }}$. Many of these defences are grounded on the transformative potential of ectogenesis, and it is full rather than partial ectogenesis that is arguably more likely to transform gestation and childbirth. ${ }^{6}$ My analysis takes as a point of departure these defences and questions whether ectogenesis can truly deliver on the transformative potential that they ascribe to it. In what follows, I present and discuss liberal arguments in favour of ectogenesis that emphasise its equality-promoting and

\footnotetext{
${ }^{i i i}$ Benefits and promises of ectogenesis are at the centre of past $^{7}$ and contemporary ${ }^{8}$ defences of this practice, and arguments showing how it ought to be regarded as a moral imperative. ${ }^{9}$ Other than for its benefits for women, ectogenesis has been defended as it could provide a 'safer, albeit more artificial' 10 environment for fetuses and as a 'solution' to the divisions and controversy surrounding abortion. This latter claim is, however, highly contested ${ }^{11-15}$
} 
freedom-promoting potential. Contra these defences, I contend that the true value of ectogenesis lies in the broader political perspective that it can advance. My analysis is conceptually and normatively women-centred in that it bypasses other potentially sound defences of ectogenesis that take fetuses or other parties into consideration.

\section{TWO SETS OF ARGUMENTS IN FAVOUR OF ECTOGENESIS}

The normative literature on ectogenesis has produced several defences of this practice. I distinguish two sets of arguments that have been advanced in favour of ectogenesis from the point of view of women. The first set of arguments stresses the equalitypromoting potential of this practice. ${ }^{17-11}$ Roughly, it points to the increased equality between men and women both in the private sphere (at home) and in the workplace that ectogenesis would make possible. It also points to ectogenesis' potential to increase equality among women. Ectogenesis would enable women who are facing biological and social constraints to reproduce to have genetically related children. The second set of arguments stresses the freedom-promoting potential of ectogenesis. ${ }^{8}{ }^{12-14}$ It refers, on the one hand, to the freedom from the burdens, restrictions, controls and potential harms of pregnancy and childbirth. On the other hand, it draws on the principle of reproductive freedom to show that ectogenesis would expand women's significant range of options and enable them to pursue their preferred parenthood project. I present these two sets of arguments in the next sections.

\section{Ectogenesis as equality-promoting}

The argument that ectogenesis could promote equality and redress natural inequalities begins with the appreciation that there are fundamental inequalities between men and women ${ }^{7-9}$ and among women. ${ }^{7}$ Some of the inequalities between men and women are directly caused by biological differences and women's unique capacity to beget children. According to this view, women carry all the burdens associated with biological reproduction: they bear physical burdens associated with gestation and childbirth $^{7815}$; they could suffer from poor physical and mental health during gestation, birth and post-delivery ${ }^{16-20}$; they could be subjected to complications of childbirth that can and often do result in death ${ }^{21} 22$; they are exposed to external control, monitoring and choice-restricting measures ${ }^{7-9}$; and they are likely to experience threats to bodily integrity and personal privacy. ${ }^{7-9}$ By contrast, men can become biological fathers without being exposed to any of these risks and burdens. Ectogenesis would be equality-promoting in that it would enable women to become mothers in the same way that men do, by reaping the benefits of having genetically related children while not experiencing the burdens associated with gestation and childbirth. For instance, following the work of radical feminist Shulamith Firestone, Singer and Wells argue that ectogenesis "can be supported on the ground that it would make a fundamental contribution toward sexual equality". ${ }^{1}$ Similarly, Tuija Takala emphasises that "if and when ectogenesis becomes a safe option it will finally make true equality between humans possible". ${ }^{10}$ The strongest case for ectogenesis in this respect is arguably Evie Kendal's, who contends that:

When added to the unequal distribution of the physical, social and financial burdens associated with pregnancy and childbirth, the claim that reproductive difference constitutes a fundamental inequality between the sexes becomes especially convincing. ${ }^{7}$
According to the author, this represents a prima facie reason in favour of ectogenesis due to the potential of this practice to redress such inequalities.

In addition, ectogenesis could redress inequalities that are indirectly caused by biological differences and women's unique capacity to beget children. ${ }^{914}$ Arguably, the burdens and responsibilities associated with social reproduction, namely, the sets of arrangements that enable a society to reproduce itself, such as domestic labour, pregnancies and childrearing, are currently largely borne by women. ${ }^{23-25}$ Following proponents of the equality-promoting potential of this practice, the burdens and responsibilities of social reproduction are placed on women due to their unique role in biological reproduction. Since ectogenesis enables the disentanglement of biological and social reproduction, the argument goes, it would succeed in redressing inequalities where other attempts to do so fail. The burdens and responsibilities of social reproduction would be more equally shared between men and women. ${ }^{710}$ For instance, Kendal argues that "ectogenesis could also provide a means of procreating that prevents many women from slipping into the regressive social norms governing childrearing". ${ }^{7}$ Similarly, Takala contends that ectogenesis would remove the biggest difference between the sexes, as it would "take away the grounds for oppression and eventually, lead to true equality". ${ }^{10}$ These views defend ectogenesis on the grounds that it has the potential to promote equality not only in begetting children but also in childrearing, which makes possible increased equality in the private sphere (ie, at home).

Another sort of male-female equality that ectogenesis promotes is in the workplace. According to this view, women's unique role in begetting children condemns them to a less competitive role in the labour market, fewer career advancements, less remuneration and from accessing certain professions. ${ }^{10}{ }^{15}$ Authors defending ectogenesis as an equality-promoting practice contend that these disadvantages and impediments to achieving full equality in the workplace are due to the breaks that women need to take to gestate children (due to their role in biological reproduction) and to fulfil childrearing responsibilities (due to their role in social reproduction). Ectogenesis would redress such inequalities by making women equally able to compete in the labour market ${ }^{711}$; to access certain professions requiring exposure to substances that can have teratogenic effects; and to fulfil roles that women cannot fulfil while gestating children due to their physical demandingness. ${ }^{7}$

Lastly, ectogenesis is defended on the grounds that it would promote equality among fertile, infertile, lesbian and transgender women. ${ }^{7}$ Ectogenesis enables women who are currently unable to gestate and birth children for social or biological reasons to have children in the same way as fertile women (ie, having children who are genetically related to them). This would equalise reproductive capacities in these different groups.

\section{Ectogenesis as freedom-promoting}

Several defences of ectogenesis are grounded in the liberating role and potential that this practice could have for women. ${ }^{14} 15$ It is hence not surprising then that the second set of arguments advanced in favour of ectogenesis revolves around its potential to promote women's freedom. A first way in which ectogenesis would achieve this is by freeing women from all the risks and burdens associated with gestating, birthing and rearing children. ${ }^{7812}$ Ectogenesis would be, in Firestone's words, a means of "freeing women from the tyranny of their sexual-reproductive roles". ${ }^{12}$ For instance, Anna Smajdor argues that: 
[F]or expectant mothers, the fact of encompassing another life in their bodies often takes a serious toll on their autonomy. Pregnant women are routinely expected to subsume their appetites and desires into those that would be in keeping with the well-being of the fetus. ${ }^{8}$

Ectogenesis would remove this 'serious toll' on women's autonomy by enabling them to have genetically related children whose well-being during gestation would not be achieved at significant costs to their mothers' freedom. Kendal makes a similar point by stressing how women's bodily integrity is severely compromised during gestation and how the social, financial and health-related burdens associated with gestation restrict women's freedom. These narratives emphasise how ectogenesis would promote women's negative freedom, that is, 'freedom from' the restricting effects of pregnancy and childbirth.

A second way in which ectogenesis would promote women's freedom is by expanding their range of significant options to pursue parenthood projects. ${ }^{1} 1314$ According to this view, this practice would represent an 'enhancement of individual freedom' ${ }^{1}$ and would be 'in the best interests of women' ${ }^{13}$ as it would provide an alternative way to gestate and birth children. This additional option would promote the freedom of all women, but it would be particularly beneficial for those women who would not be able or would not want to gestate and birth children otherwise. ${ }^{14}$ For instance, women for whom gestating and birthing is potentially highly risky or life-threatening could use ectogenesis to fulfil their parenthood projects. ${ }^{7}$ This practice would also enable women whose social circumstances make gestation and childbirth either undesirable or impossible to have genetically related children. Among these women are for instance those whose professions are either incompatible with gestating children or would expose their pregnancies to high risks. As noted by Julien Murphy, women who are smokers, drug users, casual drinkers and 'do not wish to alter their behaviour or place (their) fetus at risk' could also benefit from ectogenesis. ${ }^{15}$ These views emphasise how this practice would promote women's positive freedom, namely, the 'freedom to' beget children in ways that would not otherwise be possible. Authors advancing them directly or indirectly refer to the positive effects on and enhancement of women's reproductive freedom, namely, the freedom to decide whether or not to have children and how to have children. While reproductive freedom is often conceptualised in negative-freedom terms ${ }^{26}$ (ie, in terms of freedom from external interferences in reproductive decisions), ectogenesis would promote women's positive reproductive freedom by enabling them to beget children in the way they deem fit.

\section{THE PROBLEM WITH DEFENCES OF ECTOGENESIS}

Arguments emphasising the equality-promoting and the freedom-promoting potential of ectogenesis ground positive cases for this practice from the perspective of women. If these arguments are convincing, those committed to improving women's equality and freedom should prima facie welcome this practice. I am personally and academically committed to, and in favour of, measures that promote equality and freedom. I am also in normative agreement with both sets of arguments. What I contend in what follows, however, is that these defences of ectogenesis are limited in their reach and in their scope. Concerning their limited reach, I argue that while equalitypromoting and freedom-promoting arguments are framed in terms of enhanced equality and freedom for (all) women, ectogenesis will likely benefit only a small subset of women and not the group in the most pressing need of equality and freedom. Concerning their limited scope, I argue that these defences do not pay sufficient attention to the context in which ectogenesis would be developed and to current societal, cultural and labouring arrangements. As a result, they risk leaving the status quo unchanged.

\section{Equality and freedom, but for whom?}

Ectogenesis is considered to be equality-promoting on two accounts: it promotes equality between men and women, and between biologically and socially infertile and fertile women. Despite this depiction, the reach of defences of ectogenesis appears limited. While health-related risks, burdens and deaths caused by gestation and childbirth affect all women and can indeed be framed in terms of a 'natural inequality', ${ }^{8}$ they are not equally distributed among all women. Documented evidence shows that women belonging to ethnic minorities, poor and disabled women are at a much higher risk of experiencing complications during gestation and childbirth and of dying as a result of these complications. ${ }^{19}{ }^{27-30}$ This disparity in the distribution of the burdens and risks of gestating and birthing children among well-off, white and able women and other women can be witnessed both within and between countries. ${ }^{18} 223132$

Now, one could argue that for ectogenesis to be equalitypromoting, these groups may just need to be prioritised in their access to this practice (or at least their access to this practice would have to be secured). This would at least represent an incremental improvement of the status quo. There are, however, two sorts of barriers to achieving this: financial and cultural. Concerning financial barriers, Kendal's central claim in her defence of ectogenesis is that this practice should be state-sponsored to promote and secure equal opportunities for women. Similarly, Smajdor argues that natural inequalities "may generate a prima facie right to restitution". ${ }^{8}$ Both defences of ectogenesis hence take into consideration the potential financial constraints of developing this practice and the need for sponsoring it to enable equality-promotion for all women. The problem with these arguments is that even in developed countries with state-sponsored healthcare systems, some prioritisation decisions need to happen. For instance, in the UK, in vitro fertilisation is state-sponsored between one and three cycles, depending on one's geographical region ${ }^{\text {iv }} .^{8}$ This means that if after the number of cycles paid for by the National Health Service (NHS) no pregnancy can be established, the prospective parents must either turn to other methods to have children or attempt more cycles using their own resources. Decisions concerning resource allocation and prioritisation mean that first, even in developed countries with state-sponsored healthcare systems, it is unlikely that all biologically and socially infertile women would be granted free access to ectogenesis. For instance, it is not impossible to foresee a scenario where the former group would be prioritised over the latter, thereby achieving only partial equality with men and with other (fertile) women. Second, in developing countries and in countries without statesponsored healthcare systems, some (well-off) women would be able to access ectogenesis, while for the majority this practice would remain out of (financial) reach. Now one could argue that this is unjust and that a concern for justice would require a redress of these disparities. ${ }^{78}$ Alternatively, one could argue that state-sponsoring ectogenesis for all women may turn out

${ }^{\text {iv }}$ See for instance data from Fertility Fairness at: http://www.fertilityfairness.co.uk/nhs-fertility-services/ivf-provision-in-england/. 
to be cost-effective from a healthcare spending point of view. ${ }^{7}$ It is important to note that both these claims raise empirical questions that would need to be addressed for these claims to succeed. Addressing these questions is outside the scope of this paper. However, while I agree with Smajdor and Kendal on normative aspects of their proposals, I am sceptical as to their feasibility. The ways in which assisted reproductive technologies are currently offered in a developed country with statesponsored assisted reproduction seems to provide a prima facie reason to be sceptical that ectogenesis would be widely accessible and would hence serve as a truly universal leveller.

As mentioned earlier, the second barrier is cultural. Assisted reproductive technologies have often been criticised for being designed for and mostly accessed by white and well-off women. ${ }^{33}$ While I do not consider this as a conclusive normative argument against developing and implementing assisted reproductive technologies, it is relevant for the present discussion as poor women and women of colour have been shown to be among the least common users of these technologies. ${ }^{33-36}$ Values surrounding assisted reproductive technologies and infertility, as well as cultural understandings of them could change. But, at present, it seems that ectogenesis would be accessed byand promote the equality of-only certain women. ${ }^{37}$ Further, within equality-promoting and freedom-promoting arguments in favour of ectogenesis, the universal desirability of ends such as career advancements is taken as a given. Despite this, it is unclear whether all women would value these ends and whether women who find meaning and self-realisation in gestation and childbirth would necessarily connotate these experiences in such negative terms. Arguably, underlining claims of proponents of ectogenesis are conceptions of 'the good life' that not all women are likely to subscribe to. For many, these conceptions would seem 'WEIRD', namely, reflecting the value systems and preferences of 'Western, Educated, Industrialised, Rich and Democratic (WEIRD)' societies. ${ }^{38}$ Defenders of ectogenesis note this and contend that this practice would not be imposed on women. However, this means, on the one hand, that ectogenesis furthers the interests and preferences of only some women; on the other hand, that it may end up undermining women who find meaning and selffulfilment in gestation and childbirth. Their decisions to beget and birth children 'naturally' may be regarded as at odds with conceptions of the good life such as those advanced by proponents of ectogenesis, making opting out increasingly difficult. Ectogenesis might hence not turn out to be equality-promoting, but rather "increase divisions of class within the sexes, as well as maintaining gender differences for some groups in society". ${ }^{37}$

In addition to defences of ectogenesis emphasising its equalitypromoting potential, this practice is defended as it could promote women's freedom from the risks, burdens and invasive, autonomy-constraining measures that are often associated with gestation and childbirth. But while many if not all women experience these burdens, risks and constraints, the degree to which these are experienced varies greatly among women. Both historical and contemporary examples of control over women's (gestating) bodies indicate that control is exercised much more on the bodies of disadvantaged members of society, such as women of colour, members of ethnic minorities, and disabled and poor women. ${ }^{33} 3940$ For them, ectogenesis might not be liberating and might not promote freedom from external interference and control but rather become another instrument of oppression. The risk is that certain women, especially from disadvantaged groups, would be regarded as substandard gestators. This, in turn, may open the door to increased control and pressure to use ectogenesis to secure the safety of the fetus.
Indeed, ectogenesis could favour a problematic shift of focus from women's interests to fetal interests, depending on who the users of this practice are and on how they are regarded in society. Further, as discussed in the previous paragraph, ectogenesis may end up curtailing the free enjoyment of 'natural' gestation and childbirth for women who find meaning and self-fulfilment in these experiences. Assisted reproductive technologies such as ectogenesis could promote equality and freedom, but whether they turn out to be able to do so depends on the conditions under which they become available, on the context in which they are introduced, on who is involved in these processes and on the sort of values that frame their introduction ${ }^{\mathrm{v}}$. This brings me to the second limitation that I identify with the defences of ectogenesis outlined in the previous sections, namely, the narrow scope of these defences.

\section{A matter of context}

Ectogenesis is thought to be equality-promoting both at the level of biological reproduction and at the level of social reproduction. Moreover, ectogenesis would not only promote equality in the private sphere of the home but also in the workplace. While ectogenesis seems to be able to promote equality in biological reproduction (although not for all women, as discussed in the previous section) it is unclear whether severing the tie between biological reproduction and women would be sufficient to obtain equality in social reproduction. ${ }^{41}$ It seems that more than ectogenesis would be necessary to achieve this kind of equality. While it is possible that women's biology and their unique role in begetting children is at the root of their primary role in childrearing, this role has been socialised and has become predominant in many societies. Granted, values and norms surrounding childrearing can change and the introduction of ectogenesis could shape such values and norms. However, one issue must be noted. Other assisted reproductive technologies have created new family structures and new ways of interpreting social and biological ties, ${ }^{42}$ but have also reinforced dominant and widespread beliefs on the importance of the 'genetic tie ${ }^{43}$ and failed to challenge 'the existing order'. ${ }^{44}$ They are:

[I]n no way aimed to challenge the nuclear family, to enable women to be less defined by their reproductive capacity, to develop more feminist definitions of biology, or to dissolve the patriarchal structures of society. ${ }^{45}$

This is relevant to the present discussion as only introducing a new reproductive technology or practice (even one that so radically changes biological reproduction) does not determine how and whether such a technology or practice will go about shaping current arrangements, and social values and norms. The way technologies go about shaping extant arrangements and norms seem to depend more on how these technologies are designed, implemented and regulated, and to serve whose interests, than on the technologies themselves.

In addition to enabling equality in childrearing, ectogenesis is defended as it would allow women to equally compete with men in the labour market. Thanks to ectogenesis, women would be able to access career advancements, certain occupations that were not hitherto available to them due to their role in biological

${ }^{v}$ I am indebted to James Fletcher and Guntars Ermansons for bringing some of these issues to my attention. 
and social reproduction and be eligible for professions that would be dangerous or impossible to undertake while gestating. Defenders of ectogenesis rightly point out that the playing field is not level. Despite this, there is a sense whereby the benefit of equally competing in the labour market under the current conditions of how the labour market is organised may not be beneficial. In other words, the risk is that from the 'tyranny of pregnancy' and childbirth, women would be delivered into the tyrannical hands of a precarious, unfair and potentially exploitative labour market. The achieved equality with men would end up being the possibility of being equally exploited. Defending ectogenesis as a solution to inequality in the workplace is problematic for two reasons. First, it locates the problem in women's roles and responsibilities in gestation and childrearing rather than in an unfair and exploitative labour market. Ex hypothesis, the obstacles that women face in the workplace are the product of a system that does not accommodate (biological) differences, that does not favour a free and equal participation of both sexes in social reproduction, and that tolerates oppressive practices. Second, such framing of ectogenesis as a means to address workplace inequalities calls for solutions that change the way society reproduces itself rather than a labour market that prevents equal treatment of men and women. More attention should be devoted to changing policies, practices and values that prevent equal access to goods such as promotions and pay rises, and that do not incentivise workers to share childrearing responsibilities ${ }^{\mathrm{vi}}$. It is unclear, then, how ectogenesis would be desirable in this context. These shortcomings point to the importance of considering the context in which new (reproductive) technologies are developed and offered. In societies characterised by oppressive conditions, an exploitative labour market and disparities in terms of capacity to access and enjoy reproductive health and care benefits, ectogenesis may not be enough to subvert negative externalities generated by these features.

\section{ECTOGENESIS AS A POLITICAL PERSPECTIVE}

Many of the defences of ectogenesis outlined in the previous sections refer to the work of Firestone, one of the first thinkers to discuss the liberating potential of this practice. Sometimes they do so by quoting her punchy line 'pregnancy is barbaric'. ${ }^{12}$ Sometimes they build on her cyber-utopia that constructed this practice as one of the means to achieve the liberation of women and improve their status in society. Firestone saw in nature the cause of 'fundamental inequality' whereby "half of the human race must bear and rear the children of all of them". ${ }^{12}$ She also noted that " $[r]$ eproduction of the species cost women dearly, not only emotionally, psychologically, culturally but even in strictly material (physical) terms". ${ }^{12}$ This analysis of women's begetting capacity returns in contemporary defences of ectogenesis, where this practice is presented as a solution to women's malaises and a means to promote equality and freedom. Between Firestone's radical proposal and contemporary defences of ectogenesis, however, something important has been lost. Firestone's defence of ectogenesis was not limited to a techno-fix of social, political and cultural problems. Rather, it represented one aspect of a much broader proposal to change the labour market, the role of

\footnotetext{
${ }^{\text {vi }}$ It must be noted that I am not suggesting that interventions aimed at changing social arrangements necessarily need to be preferred to those aimed at changing biology. Rather, my argument is that the former set of interventions is problematic insofar as it is proposed as a solution to unjust social arrangements and used as a way to address such injustice.
}

women in society and how society was organised more generally. To be truly liberating, ectogenesis would have had to be embedded in a comprehensive and radical programme for (feminist) revolution, leading to the elimination of (sexual) classes. Firestone dreaded the introduction of ectogenesis without a corresponding effort to change the society in which this practice would have had to be introduced ${ }^{46}$ :

Though the sex class system may have originated in fundamental biological conditions, this does not guarantee once the biological basis of their oppression has been swept away that women and children will be freed. On the contrary, the new technology, [...] may be used against them to reinforce the entrenched system of exploitation. $^{12}$

This perspective and the revolutionary undertones accompanying Firestone's case for ectogenesis often do not appear in contemporary defences of this practice. Today, despite improvements in women's standing in society, we are far from the utopian scenarios envisaged by Firestone. As I have argued in the previous sections, defending ectogenesis without considering the context in which this technology would be introduced may result in promoting the equality and freedom of only certain women or in not improving women's equality and freedom altogether.

At this point, two questions remain open: whether or not ectogenesis should still be defended and whether or not it could truly deliver on its equality-promoting and freedom-promoting potential. In other words, what value, if any, does ectogenesis have? In this respect, I have a proposal to advance. Liberal defences of ectogenesis characterise this practice as a means to achieve greater equality and freedom for women. Despite this, my argument is that ectogenesis, alone, would not be able to deliver on these promises. Moreover, this practice may, in some instances, end up leaving the status quo unchanged or worsen it. As it is currently defended, ectogenesis is a red herring. It distracts from the most urgent and pressing needs of certain women and it locates the problem in women's biological capacities rather than in current societal structures and arrangements. Contra these views, I argue that the value of ectogenesis, and of defences thereof, lies in the political perspective that it can advance.

In order to reconceptualise defences of ectogenesis in political terms, Silvia Federici's, ${ }^{47}$ Mariarosa Dalla Costa's and Selma James ${ }^{48}$ readings of the international feminist campaign 'Wages for Housework' provide a useful frame. This campaign began in the 1970s in Italy and called for the political recognition of the reproductive labour performed by women in their homes (such as housework and childcare). Reproductive labour had to be conceived of as work and its active contribution to the production of surplus value recognised. ${ }^{49}$ Reconstructing what was considered a 'natural' female duty as work was a way to claim its belonging to the sphere of waged labour and to demand the rejection of both 'its devaluation as work and its overvaluation as labour of love'. ${ }^{49}$ It is a point of contention within feminist scholarship as to whether the demand for wages for housework should be taken literally or metaphorically. Relevant to the present discussion are Federici's, and Della Costa and James' interpretations of this demand as a political perspective. According to them, what mattered was not the content of the demand, that is, proposing reformist policies that would extend waged labour to include reproductive labour. It was not a demand for money. Rather, what mattered was the political perspective and the provocation that the demand advanced. Its political perspective called for rethinking, scrutinising and 
making visible the position of women within the labour market, the family and society more generally. It was a demand for performing the analytical work that would render visible structures and dynamics that were hitherto not being subjected to critical scrutiny. The demand for wages for housework represented also a provocation. Kathi Weeks emphasises this dimension of the demand and its performative power, which was meant to elicit 'subversive commitments, collective formations and political hopes'. ${ }^{49}$ The demand for wages for housework was about unionising and joining forces to collectively claim the power to change society, it was an indispensable condition to begin to struggle $^{47}$ against the current organisation of labour and society.

There is something to learn from these readings of the Wages for Housework campaign. To deliver on its equality-promoting and freedom-promoting potential, defences of ectogenesis need to be conceived in terms of and including elements that advance a broad political perspective. This political perspective allows for the scrutiny of and a critical engagement with the risks and burdens of pregnancy and childbirth, as well the unfair distribution of childrearing responsibilities between men and women. It also enables to critically appraise women's positions in society, their role in social reproduction and the effects of having such role on their lives at home and in the workplace. This provides a chance to locate the problem away from women's roles and responsibilities in gestation and childrearing and in the structures that prevent their enjoyment of equality and freedom. It also opens up discussions on solutions that can be valuable for all women and that pay attention to the contexts in which they are trialled. Relatedly, ectogenesis should also be defended as a provocation, one that demands: better medical and social services for gestating women; a decrease in the medical hazards associated with gestation and childbirth; better working (and living) conditions for future mothers, gestating mothers, mothers and women more generally; and a true redistribution of the burdens and responsibilities of social reproduction. What is needed, in other words, is a "woman-centred reproductive agenda that makes visible the needs of all women, particularly poor women and women of colour". ${ }^{15}$

\section{CONCLUSION}

In this paper, I have presented defences of ectogenesis that ground a positive case for this technology in its potential to promote women's equality and freedom. I have argued thatalthough sympathising with their normative commitmentsthese defences are limited in their reach and scope. Their reach is limited in that they do not account for financial and cultural barriers that would prevent all women from enjoying increased equality and freedom. Their scope is also limited as they lack an appreciation of the context in which this practice would be introduced. To address these limitations, I propose that not ectogenesis as such, but the political perspective that it can advance should be regarded as important and defended.

Correction notice This article has been amended since it was first published online.

Twitter Giulia Cavaliere @giuli_cavaliere

Acknowledgements I am grateful to Lorenzo Del Savio, Claire Horn and Silvia Camporesi for their helpful comments on previous versions of this paper. I would also like to thank two anonymous reviewers for providing constructive feedback on this paper. Lastly, I am indebted to the students who took Ethics of Emerging Biotechnologies at King's College London in 2018 and 2019. I have learned a lot from our exchanges on this issue.

Contributors I am the sole author of this manuscript.
Funding The authors have not declared a specific grant for this research from any funding agency in the public, commercial or not-for-profit sectors.

Competing interests None declared.

Patient consent for publication Not required.

Provenance and peer review Not commissioned; externally peer reviewed.

\section{ORCID iD}

Giulia Cavaliere http://orcid.org/0000-0001-8703-1499

\section{REFERENCES}

1 Singer P, Ectogenesis WD. Ectogenesis. In: Gelfand S, Shook JR, eds. Artificial womb technology and the future of human reproduction. Amsterdam, NL: Rodopi, 2006: 9-25.

2 Deglincerti A, Croft GF, Pietila LN, et al. Self-organization of the in vitro attached human embryo. Nature 2016:533(7602):251-4.

3 Shahbazi MN, Jedrusik A, Vuoristo $S$, et al. Self-organization of the human embryo in the absence of maternal tissues. Nat Cell Biol 2016;18(6):700-8.

4 Hyun I, Wilkerson A, Johnston J. Embryology policy: revisit the 14-day rule. Nature 2016;533(7602):169-71.

5 Partridge EA, Davey MG, Hornick MA, et al. An extra-uterine system to physiologically support the extreme premature lamb. Nat Commun 2017;8(1):15112.

6 Jackson E. Degendering reproduction? Med Law Rev 2008;16(3):346-68.

7 Kendal E. Equal opportunity and the case for state sponsored ectogenesis. Basingstoke, UK: Palgrave, 2015.

8 Smajdor A. The moral imperative for ectogenesis. Camb Q Healthc Ethics 2007;16(03):336-45.

9 Smajdor A. In defense of ectogenesis. Camb Q Healthc Ethics 2012;21(1):90-103.

10 Takala T. Human before sex? Ectogenesis as a way to equality. In: Simonstein F, ed. Reprogen-ethics and the future of gender. Dordrecht, NL: Springer, 2009: 187-95.

11 Simonstein F. Artificial reproduction technologies (RTs) - all the way to the artificial womb? Med Health Care Philos 2006;9(3):359-65.

12 Firestone $\mathrm{S}$. The dialectic of sex: the case for feminist revolution. 2nd Edition. London, UK: Verso, 2015. http://liveunitedblog.org/the-dialectic-of-sex-the-case-for-feministrevolution-ebook-good-reads-shulamith-firestone.pdf

13 Pence G. What's so good about natural motherhood? (In praise of unnatural gestation). In: Ectogenesis. Artificial womb technology and the future of human reproduction. Amsterdam, NL: Rodopi, 2006: 77-88. https://repository.library. georgetown.edu/handle/10822/976475

14 Sander-Staudt M. Of machine born? A feminist assessment of ectogenesis and artificial wombs. In: Ectogenesis. Artificial womb technology and the future of human reproduction. Amsterdam, NL: Rodopi, 2006: 109-28. https://repository.library. georgetown.edu/handle/10822/976473

15 Murphy JS. Is pregnancy necessary? Feminist concerns about ectogenesis. Hypatia 1989:4(3):66-84

16 Garthus-Niegel S, von Soest T, Vollrath ME, et al. The impact of subjective birth experiences on post-traumatic stress symptoms: a longitudinal study. Arch Womens Ment Health 2013:16(1):1-10.

17 O'Hara MW, Wisner KL. Perinatal mental illness: definition, description and aetiology. Best Pract Res Clin Obstet Gynaecol 2014;28(1):3-12.

18 World Health Organization. Managing complications in pregnancy and childbirth: a guide for midwives and doctors. Geneva, CH: World Health Organization, 2017 https://apps.who.int/iris/bitstream/handle/10665/255760/9789241565493-eng.pdf; jsessionid=E93E476DF235514D883160E6DF7E05E6? sequence $=1$

19 Creanga AA, Berg CJ, Ko JY, et al. Maternal mortality and morbidity in the United States: where are we now? J Womens Health 2014;23(1):3-9.

20 Creanga AA, Bateman BT, Kuklina EV, et al. Racial and ethnic disparities in severe maternal morbidity: a multistate analysis, 2008-2010. Am J Obstet Gynecol 2014;210(5):435.e1-8

21 Lo JO, Mission JF, Caughey AB. Hypertensive disease of pregnancy and maternal mortality. Curr Opin Obstet Gynecol 2013:25(2):124-32.

22 World Health Organization. Trends in maternal mortality: 1990 to 2015. Estimates by WHO, UNICEF, UNFPA, world bank group and the United nations population division. Geneva, CH:World Health Organization, 2015. http://www.who.int reproductivehealth/publications/monitoring/maternal-mortality-2015/en/

23 Perez CC. Invisible women: exposing data bias in a world designed for men. London, UK: Chatto \& Windus, 2019. https://www.amazon.co.uk/Invisible-Women-ExposingWorld-Designed/dp/1784741728

24 Ferrant G, Pesando LM, Nowacka K. Unpaid care work: the missing link in the analysis of gender gaps in labour outcomes. Issy-les-Moulineaux, FR: OECD Development Centre, 2014. http://www.oecd.org/dev/development-gender/unpaid_care_work.pdf

25 The World Bank. Proportion of time spent on unpaid domestic and care work, male (\% of 24 hour day). Available: https://data.worldbank.org/indicator/SG.TIM.UWRK. MA?view=chart [Accessed 5 Jul 2019].

26 Mills C. Reproductive autonomy as self-making: procreative liberty and the practice of ethical subjectivity. J Med Philos 2013;38(6):639-56.

27 Bryant AS, Worjoloh A, Caughey AB, et al. Racial/ethnic disparities in obstetric outcomes and care: prevalence and determinants. Am J Obstet Gynecol 2010;202(4):335-43. 
28 Ghulmiyyah L, Sibai B. Maternal mortality from preeclampsia/eclampsia. Semin Perinatol 2012;36(1):56-9.

29 Tucker MJ, Berg CJ, Callaghan WM, et al. The Black-White disparity in pregnancyrelated mortality from 5 conditions: differences in prevalence and case-fatality rates. Am J Public Health 2007;97(2):247-51.

30 Zwart JJ, Jonkers MD, Richters A, et al. Ethnic disparity in severe acute maternal morbidity: a nationwide cohort study in the Netherlands. Eur J Public Health 2011;21(2):229-34

31 Ronsmans C, Graham WJ. Maternal mortality: who, when, where, and why. Lancet 2006:368(9542):1189-200.

32 Alkema L, Chou D, Hogan D, et al. Global, regional, and national levels and trends in maternal mortality between 1990 and 2015, with scenario-based projections to 2030: a systematic analysis by the un maternal mortality estimation Inter-Agency group. The Lancet 2016;387(10017):462-74.

33 Roberts DE. Killing the black body. Race, reproduction and the meaning of liberty. New York, NY: Pantheon, 1997.

34 Nachtigall RD. International disparities in access to infertility services. Fertil Steril 2006:85(4):871-5.

35 Feinberg EC, Larsen FW, Wah RM, et al. Economics may not explain Hispanic underutilization of assisted reproductive technology services. Fertil Steril 2007:88(5):1439-41.

36 McCarthy-Keith DM, Schisterman EF, Robinson RD, et al. Will decreasing assisted reproduction technology costs improve utilization and outcomes among minority women? Fertil Steril 2010;94(7):2587-9.

37 Bradley H. Gendered futures: Reproduction and production in women's lives. In: Simonstein F, ed. Reprogen-ethics and the future of gender. Dordrecht, NL: Springer, 2009: 119-32

38 Henrich J, Heine SJ, Norenzayan A. Most people are not WEIRD. Nature 2010:466(7302):29
39 Connelly M. Fatal misconception. The struggle to control world population Cambridge, MA: The Belknap Press of Harvard University Press, 2008.

40 Murphy M. The economization of life. Durham, NC: Duke University Press, 2017. https://www.dukeupress.edu/the-economization-of-life

41 Woolfrey J, Gelfand S, Shook JR. Ectogenesis: Liberation, technological tyranny, or just more of the same? In: Ectogenesis. artificial womb technology and the future of human reproduction. Amsterdam, NL: Rodopi, 2006. https://repository.library. georgetown.edu/handle/10822/976472

42 Palacios-González C, Harris J, Testa G. Multiplex parenting: IVG and the generations to come. J Med Ethics 2014:40(11):752-8.

43 Roberts DE. The genetic tie. Univ Chic Law Rev 1995;62(1):209-73.

44 Griffiths $D$. The (re) production of the genetically related body in law, technology and culture: mitochondria replacement therapy. Health Care Anal 2016;24(3):196-209

45 Franklin S. The dialectic of sex: Shulamith Firestone revisited. Text Publ. Online Dep. Sociol. Lanc. Univ, 1998. Available: http://sex.ncu.edu.tw/members/Ning/class/ graduate/firestone/firestone1/Sarah\%20Franklin,\%20The\%20Dialectic\%20 of\% 20Sex\%20Shulamith\%20Firestone\%20Rev.htm [Accessed 5 Jul 2019].

46 Limon C. From surrogacy to Ectogenesis: reproductive justice and equal opportunity in neoliberal times. Aust Fem Stud 2016;31(88):203-19.

47 Federici S, Malos E. Wages against housework. In: The politics of housework. Cheltenham, UK: New Clarion, 1995: 187-94.

48 Dalla Costa M, James S. The power of women and the subversion of the community. Bristol, UK: Falling Wall Press, 1975.

49 Weeks K. The problem with work: feminism, Marxism, antiwork politics, and postwork imaginaries. Durham, NC: Duke University Press, 2011.

50 Romanis EC. Artificial womb technology and the frontiers of human reproduction: conceptual differences and potential implications. J Med Ethics 2018:44(11):751-5 